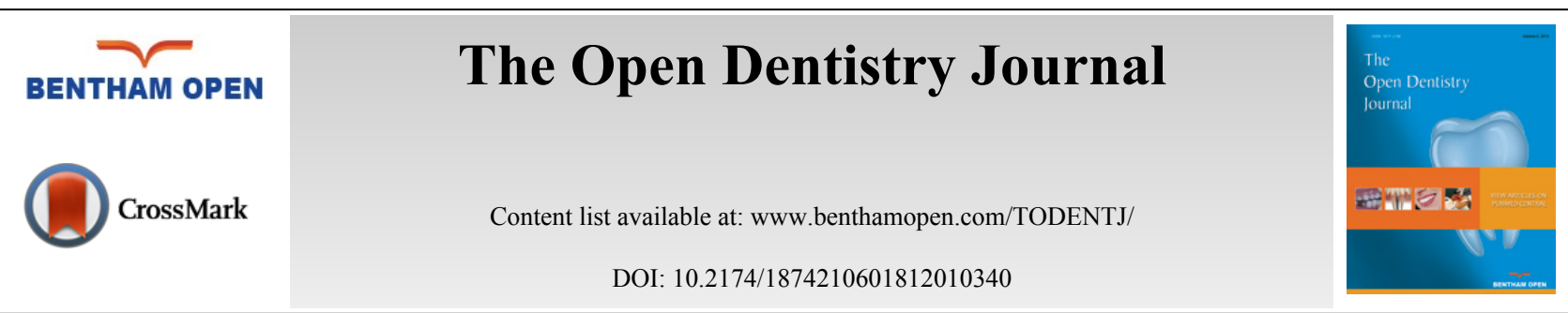

REVIEW ARTICLE

\title{
Oral Ketorolac with Inferior Alveolar Nerve Block for Irreversible Pulpitis: A Systematic Review and Meta-analysis
}

\author{
Gowri Sivaramakrishnan $^{1, *}$ and Kannan Sridharan ${ }^{2}$ \\ ${ }^{I}$ Department of Oral Health, College of Medicine, Nursing and Health Sciences, Fiji National University, Brown Street, \\ Suva, Fiji \\ ${ }^{2}$ Department of Pharmacology and Therapeutics, College of Medicine and Medical Sciences, Arabian Gulf University, \\ Manama, Bahrain
}

Received: August 28, 2017

Revised: April 13, 2018

Accepted: April 24, 2018

\section{Abstract: \\ Background:}

Ketorolac has advantages over other analgesics as a pre-anaesthetic medication. Considering this in mind, the present meta-analysis aims to identify the effect of oral ketorolac premedication on the anaesthetic efficacy of Inferior Alveolar Nerve Block (IANB) in patients with irreversible pulpitis.

\section{Methods:}

Full-texts of eligible studies were obtained from electronic databases. The extracted data was analysed using non-Cochrane mode in RevMan 5.0 software. Relative risk [95\% CI] was calculated for the success of IANB.

Results:

Four studies were included for the final review. The success rate of IANB on 221 patients with relative risk of 1.87 [1.36, 2.56] was statistically significant favouring ketorolac. The mean difference for VAS in 171 patients was not statistically significant $\{-13.55$ $[-33.91,6.82]\}$.

\section{Conclusion:}

Oral ketorolac can be successfully administered as a premedication before conventional inferior alveolar nerve block for endodontic treatment for irreversible pulpitis.

Keywords: Ketorolac, Pre-medication before IANB, Irreversible pulpitis, Pain, Root canal treatment, Endodontics.

\section{INTRODUCTION}

Management of pain is one most important aspect to be addressed while planning treatment procedures in dentistry, especially endodontic treatment. Inferior Alveolar Nerve Block (IANB) has been routinely used to achieve profound anaesthesia during endodontic treatment. However, the success rate of IANB alone has been reported to vary between 15 and 57\% [1]. The practice of prescribing pre-medication using various Non-Steroidal Anti-Inflammatory Drugs (NSAIDs) and opioid analgesics for pulpal inflammation, prior to local anaesthesia, has been explored in various randomised controlled trials [2 - 5]. NSAIDs act by inhibiting cyclooxygenase and recently scavenging of reactive intracellular products has been attributed for its anti-inflammatory activity [6]. Amongst the NSAIDs, ketorolac has beneficial effects in patients with exaggerated or severe inflammation and it can be used even as an opioid-sparing

\footnotetext{
* Address correspondence to this author at the Department of Oral Health, College of Medicine, Nursing and Health Sciences, Fiji National University, Brown Street, Suva, Fiji; Tel: +6799090572; E-mail: gowri.sivaramakrishnan@gmail.com
} 
analgesic drug [7]. Parenteral ketorolac has been suggested as an appropriate analgesic in the pre-hospital settings in patients with acute pain [8]. Patients with irreversible pulpitis have moderate to severe type of odontogenic pain consequent to which the success of IANB may be low. In a recent study, it was observed that pulpitis patients without pain have better success rate for IANB than with pain [9]. Hence, various investigators have tried ketorolac as a preanaesthetic medication for improving success of IANB. However, until date, there is no systematic compilation on such studies to observe the relative effect estimate of ketorolac with other pre-anaesthetic drugs. Thus, we carried out the present systematic review and meta-analysis to identify the anaesthetic efficacy of inferior alveolar nerve block after pre-medication with oral ketorolac, for endodontic treatment of tooth diagnosed with irreversible pulpitis.

\section{MATERIALS AND METHODS}

\subsection{Information Sources and Search Strategy}

The protocol for this review was registered with International Prospective Register of Systematic Reviews (PROSPERO) with the registration number CRD42016039273. The review protocol can be accessed at http://www.crd.york.ac.uk/PROSPERO/register_new_review.asp?RecordID=39273\&UserID=16309

A through literature search was conducted and completed on 20 May 2016 on Medline (via PubMed), Cochrane central register of clinical trials (CENTRAL) and Database of Abstracts of Reviews of Effects (DARE) using ketorolac [tiab] and inferior alveolar nerve block [tiab] as keywords. This search was further supplemented by hand searching of references from eligible studies. Studies published only in English language were included.

\subsection{Eligibility Criteria}

Only those studies with randomized controlled design with the following requirements were included in the present study:

1. Type of participants: Patients with irreversible pulpitis in any tooth and requiring endodontic treatment under inferior alveolar nerve block with lignocaine using conventional technique.

2. Type of intervention: Oral ketorolac pre-medication before conventional inferior nerve block with lignocaine.

3. Comparison: Placebo or any other oral pre-medication with any drug before inferior nerve block with lignocaine.

4. Outcome: The success rate of the Inferior Alveolar Nerve Block (IANB) and the assessment of pain measured with Visual Analog Scale (VAS).

\subsection{Study Procedure}

Two authors independently screened all the data and identified abstracts for possible inclusion. Full-text articles were obtained for all the eligible studies. A pre-tested data extraction form was created and both the authors independently extracted trial site, year, trial methods, participants, interventions, and outcomes. Disagreement between the authors was resolved through discussion. The extracted data were analysed using non-Cochrane mode in RevMan 5.0 software. The methodological quality of eligible trials was assessed using the Cochrane collaboration's tool for assessing the risk of bias. We followed the guidance to assess whether trials took adequate steps to reduce the risk of bias across six domains: sequence generation, allocation concealment, blinding (of participants, personnel, and outcome assessors), incomplete outcome data, selective outcome reporting, and other sources of bias. The judgment was categorized into the low, high or unclear risk of bias [10]. Due to a limited number of studies, publication bias could not be checked. Percent difference between the experimental (ketorolac group) and control (placebo or any other drug) group were assessed and the mean difference in the percent and percent standard error were considered for final assessment. Relative risk $[95 \% \mathrm{CI}]$ was calculated for the success of IANB. The heterogeneity between the studies was assessed using the Forest plot visually, $\mathrm{I}^{2}$ statistics wherein more than $50 \%$ was considered to have moderate to severe heterogeneity and Chi-square test with a statistical $P$-value of less than 0.10 to indicate statistical significance. Randomeffect models were used in case of moderate heterogeneity. The present meta-analysis was conducted and presented in accordance with Preferred Reporting Items for Systematic Reviews and Meta-Analyses (PRISMA) guidelines [11]. 


\section{RESULTS}

\subsection{Search Results}

Eight studies were obtained during the screening, of which four were found to be eligible to be included for the final review and quantitative synthesis (Fig. 1). Table 1 lists the key characteristics of the included studies [12 - 15]. A summary of risk of bias of included studies is depicted in Fig. (2).

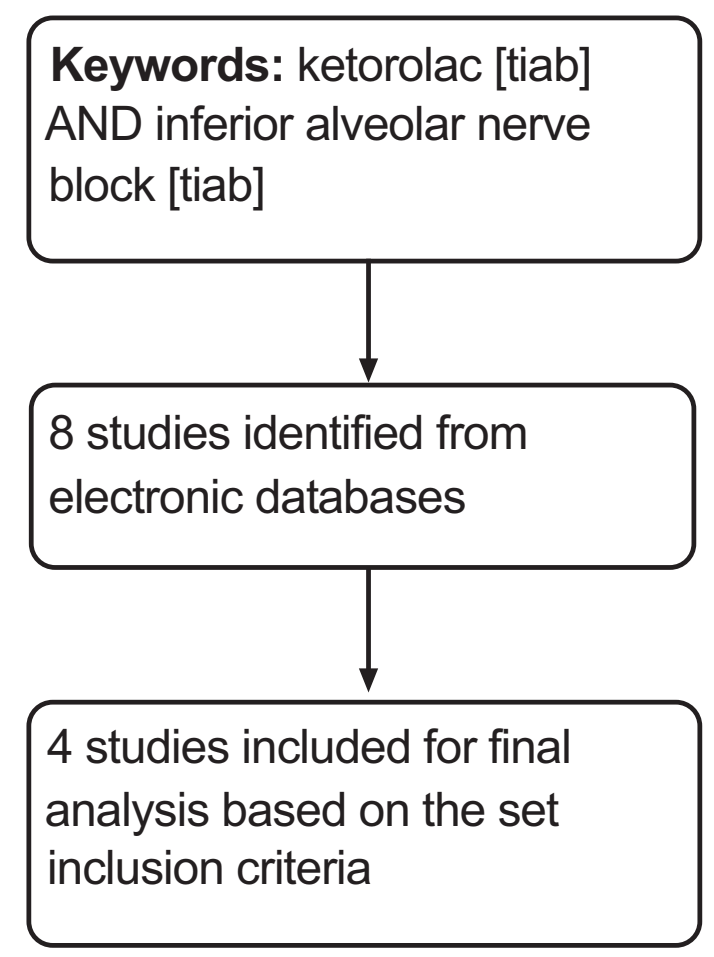

Fig. (1). Study flow diagram.

Table 1. Key characteristics of the included studies.

\begin{tabular}{|c|c|c|c|c|}
\hline Author & Participants & Intervention & Control & Outcome \\
\hline $\begin{array}{c}\text { Jena A } \\
2013^{8}\end{array}$ & $\begin{array}{l}100 \text { Adult patients requiring } \\
\text { endodontic treatment for } \\
\text { tooth diagnosed with } \\
\text { irreversible pulpitis }\end{array}$ & $\begin{array}{c}20 \text { patients-Oral ketorolac } 10 \mathrm{mg} \text { pre- } \\
\text { medication after which conventional } \\
\text { inferior alveolar nerve block will be } \\
\text { administered. }\end{array}$ & $\begin{array}{c}20 \text { patients-placebo with sugar coated pills } \\
20 \text { patients-ibuprofen } 600 \mathrm{mg} \\
20 \text { patients-etodolac with } \\
\text { paracetamol( } 400 \mathrm{mg}+500 \mathrm{mg}) \\
20 \text { patients-aceclofenac with } \\
\text { paracetamol }(100 \mathrm{mg}+500 \mathrm{mg}) \\
\text { After all the above mentioned control, } \\
\text { conventional inferior alveolar nerve block will } \\
\text { be administered. }\end{array}$ & $\begin{array}{l}\text { Visual analog } \\
\text { scale } \\
\text { Overall success of } \\
\text { inferior alveolar } \\
\text { nerve block }\end{array}$ \\
\hline $\begin{array}{l}\text { Ganguly } \\
\text { SA } \\
2016^{9}\end{array}$ & $\begin{array}{l}126 \text { adult patients requiring } \\
\text { endodontic treatment for } \\
\text { tooth diagnosed with } \\
\text { irreversible pulpitis }\end{array}$ & $\begin{array}{c}42 \text { patients- ketorolac pre-medication } \\
\text { after which conventional inferior } \\
\text { alveolar nerve block will be } \\
\text { administered }\end{array}$ & $\begin{array}{c}42 \text { patients- diclofenac potassium } \\
42 \text { patients- Placebo } \\
\text { After all the above mentioned control, } \\
\text { conventional inferior alveolar nerve block will } \\
\text { be administered. }\end{array}$ & \begin{tabular}{|c|} 
Visual analog \\
scale \\
Overall success of \\
inferior alveolar \\
nerve block \\
\end{tabular} \\
\hline $\begin{array}{c}\text { Aggarwal } \\
\text { V } \\
2010^{10}\end{array}$ & $\begin{array}{l}62 \text { adult patients requiring } \\
\text { endodontic treatment for } \\
\text { tooth diagnosed with } \\
\text { irreversible pulpitis }\end{array}$ & $\begin{array}{c}24 \text { patients- ketorolac } 10 \mathrm{mg} \text { pre- } \\
\text { medication after which conventional } \\
\text { inferior alveolar nerve block will be } \\
\text { administered }\end{array}$ & $\begin{array}{c}24 \text { patients- ibuprofen } 300 \mathrm{mg} \\
24 \text { patients- placebo } \\
\text { After all the above mentioned control, } \\
\text { conventional inferior alveolar nerve block will } \\
\text { be administered. }\end{array}$ & \begin{tabular}{|} 
Visual analog \\
scale \\
Overall success of \\
inferior alveolar \\
nerve block
\end{tabular} \\
\hline $\begin{array}{c}\text { Yadav M } \\
2015^{11}\end{array}$ & $\begin{array}{l}50 \text { adult patients requiring } \\
\text { endodontic treatment for } \\
\text { tooth diagnosed with } \\
\text { irreversible pulpitis }\end{array}$ & $\begin{array}{c}25 \text { patients -ketorolac } 10 \mathrm{mg} \text { pre- } \\
\text { medication after which conventional } \\
\text { inferior alveolar nerve block will be } \\
\text { administered after buccal and lingual } \\
\text { infiltrations. }\end{array}$ & $\begin{array}{c}25 \text { patients- no pre-medication. Conventional } \\
\text { inferior alveolar nerve block will be } \\
\text { administered after buccal and lingual } \\
\text { infiltrations. }\end{array}$ & $\begin{array}{c}\text { Overall success of } \\
\text { inferior alveolar } \\
\text { nerve block }\end{array}$ \\
\hline
\end{tabular}




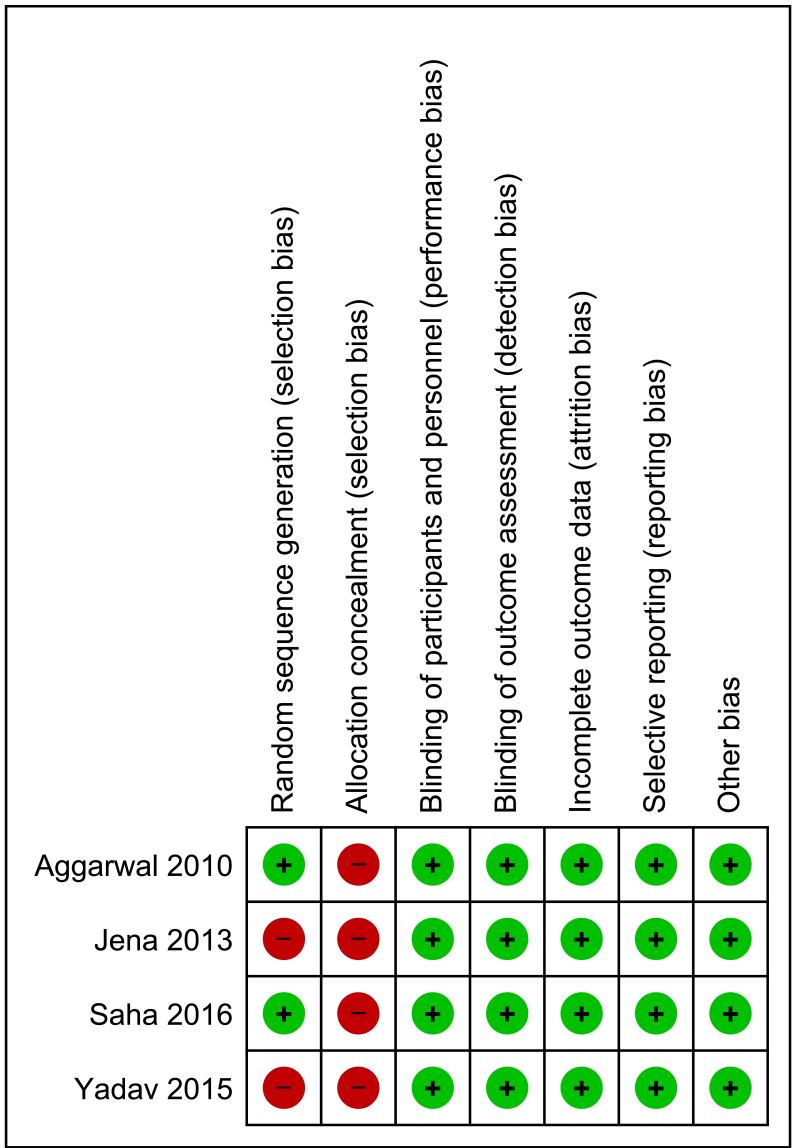

Fig. (2). Summary of risk of bias.

\subsection{Pooled Results}

\subsubsection{Success Rate of IANB}

All the four included studies evaluated the success rate of IANB with ketorolac pre-medication in comparison with placebo, in a total of 221 study participants in which 65 successful events were observed in the ketorolac group and 35 in the placebo group. The pooled relative risk for the success of block was observed to be 1.87 [1.36, 2.56] and was statistically significant favouring the use of ketorolac as a pre-anaesthetic medication (Fig. 3).

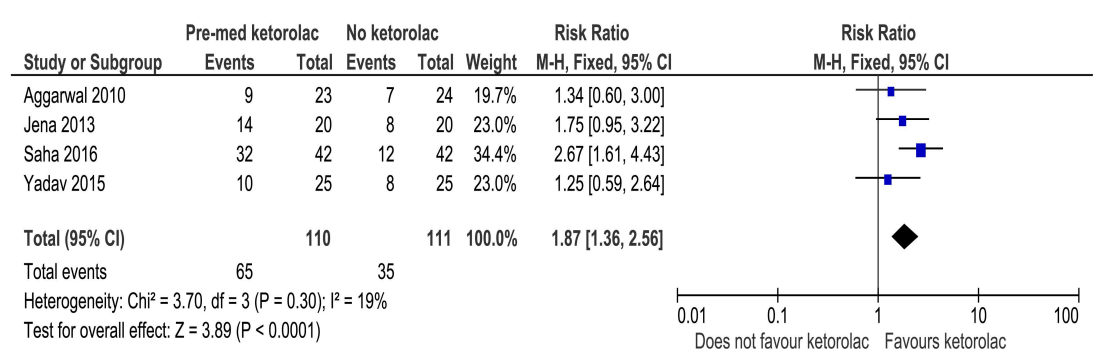

Fig. (3). Forest plot of success rate of IANB.

\subsubsection{VAS}

Three out of four studies compared VAS for pain between the ketorolac and placebo group in a total of 171 patients. The pooled mean difference was not statistically significant between the groups with the MD being -13.55 [-33.91, 6.82] (Fig. 4). 


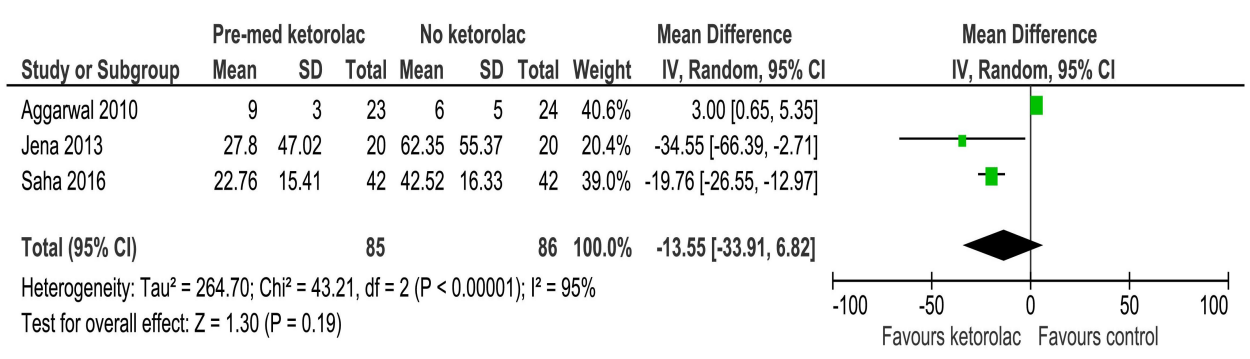

Fig. (4). Forest plot of VAS.

\section{DISCUSSION}

This systematic review aims to identify the anaesthetic efficacy of conventional inferior alveolar nerve block using lignocaine when pre-medication using oral ketorolac is administered.

Inferior alveolar nerve block using lignocaine and adrenaline has been routinely used to gain profound analgesia before endodontic treatment of teeth diagnosed with irreversible pulpitis. However, 90\% of the practitioners experienced difficulties in achieving profound analgesia. In specific, a greater number of failures have been reported to occur with inferior alveolar nerve block [16] especially in teeth manifesting with irreversible pulpitis [17]. Various reasons reported for this failure include anxiety and fear, accessory innervation and concentration and volume of local anaesthetic and vasoconstrictor [18]. Keeping the failure rates in mind, studies focussed on using pre-medication with NSAID's and steroids and identified the anaesthetic efficacy of inferior alveolar nerve block after pre-medication. A systematic review on the effect of premedication on inferior alveolar nerve block was compiled by Lapidius et al. However not all studies were included in the systematic analysis [19].

Pre-operative medication has been suggested as a measure to increase the efficacy of inferior alveolar nerve block. Various NSAID's such as ibuprofen, ketorolac, diclofenac and steroids like dexamethasone have been tried in various randomised controlled trials $[4,5,12]$. Ketorolac has been a preferred due to its advantages over other NSAID's. These include less likely alterations to the bleeding time, less likely to cause acute renal failure in patients with pre-existing renal impairment, less likely combination reactions when co-administered with other drugs and single dose administration [20]. Considering the advantages of ketorolac over other NSAID's this systematic review and metaanalysis identified the anaesthetic efficacy of inferior alveolar nerve block after pre-medication with ketorolac. Apart from ketorolac, other non-steroidal anti-inflammatory drugs such as ibuprofen and acetaminophen (in combination) [21]. Recently, Praveen et al. [22] conducted a trial comparing ketorolac with prednisolone and the latter drug was observed with more persistent effect than ketorolac and placebo. Apart from oral administration, ketorolac has also been shown to be effective as buccal administration [23]. In contrast, adjuvant ketorolac with nitrous oxide has not been shown to have any additive analgesic effect in patients with symptomatic pulpitis [24].

The four studies included in the systematic review and meta-analysis identified ketorolac oral pre-medication had a statistically significant effect on the success rate of an inferior alveolar nerve block in patients with irreversible pulpitis. However, the pain scale as measured by VAS was not statistically significant. The study is limited in the fact that EMBASE could not be searched for appropriate studies. Nevertheless, checking the cross-references of the included studies is likely to negate this issue.

\section{CONCLUSION}

Considering the advantages of ketorolac over other agents and the results obtained in the present study, we conclude from the systematic review and meta-analysis that oral premedication using ketorolac should be considered before conventional inferior alveolar nerve block for endodontic treatment of irreversible pulpitis. However, long-term randomized controlled trials are warranted.

\section{CONSENT FOR PUBLICATION}

Not applicable.

\section{CONFLICT OF INTEREST}

The authors declare no conflict of interest, financial or otherwise. 


\title{
ACKNOWLEDGEMENTS
}

\author{
Declared none.
}

\section{REFERENCES}

[1] Reader A, Nusstein J, Drum M. Endodontic anaesthesia -Successful local anaesthesia for restorative dentistry and endodontics. Hanover Park II: Quintessence Publishings 2011; 131-48.

[2] Parirokh M, Ashouri R, Rekabi AR, et al. The effect of premedication with ibuprofen and indomethacin on the success of inferior alveolar nerve block for teeth with irreversible pulpitis. J Endod 2010; 36(9): 1450-4.

[http://dx.doi.org/10.1016/j.joen.2010.05.007] [PMID: 20728707]

[3] Modaresi J, Dianat O, Mozayeni MA. The efficacy comparison of ibuprofen, acetaminophen-codeine, and placebo premedication therapy on the depth of anesthesia during treatment of inflamed teeth. Oral Surg Oral Med Oral Pathol Oral Radiol Endod 2006; 102(3): 399-403. [http://dx.doi.org/10.1016/j.tripleo.2005.10.053] [PMID: 16920550]

[4] Lindemann M, Reader A, Nusstein J, Drum M, Beck M. Effect of sublingual triazolam on the success of inferior alveolar nerve block in patients with irreversible pulpitis. J Endod 2008; 34(10): 1167-70. [http://dx.doi.org/10.1016/j.joen.2008.07.013] [PMID: 18793913]

[5] Aggarwal V, Singla M, Rizvi A, Miglani S. Comparative evaluation of local infiltration of articaine, articaine plus ketorolac, and dexamethasone on anesthetic efficacy of inferior alveolar nerve block with lidocaine in patients with irreversible pulpitis. J Endod 2011; 37(4): 445-9.

[http://dx.doi.org/10.1016/j.joen.2011.01.016] [PMID: 21419287]

[6] Fernandes E, Costa D, Toste SA, Lima JL, Reis S. In vitro scavenging activity for reactive oxygen and nitrogen species by nonsteroidal antiinflammatory indole, pyrrole, and oxazole derivative drugs. Free Radic Biol Med 2004; 37(11): 1895-905. [http://dx.doi.org/10.1016/j.freeradbiomed.2004.09.001] [PMID: 15528048]

[7] Joishy SK, Walsh D. The opioid-sparing effects of intravenous ketorolac as an adjuvant analgesic in cancer pain: Application in bone metastases and the opioid bowel syndrome. J Pain Symptom Manage 1998; 16(5): 334-9. [http://dx.doi.org/10.1016/S0885-3924(98)00081-5] [PMID: 9846029]

[8] Mallinson TE. A review of ketorolac as a prehospital analgesic. J Paramedic Practice 2017; 9: 522-7. [http://dx.doi.org/10.12968/jpar.2017.9.12.522]

[9] Tortamano IP, Siviero M, Costa CG, Buscariolo IA, Armonia PL. A comparison of the anesthetic efficacy of articaine and lidocaine in patients with irreversible pulpitis. J Endod 2009; 35(2): 165-8. [http://dx.doi.org/10.1016/j.joen.2008.10.020] [PMID: 19166765]

[10] Higgins JPT, Green S. Cochrane Handbook for Systematic Reviews of Interventions. 5.1.0 2011. Available from www.cochrane-handbook.org

[11] Moher D, Liberati A, Tetzlaff J, Altman DG. Preferred reporting items for systematic reviews and meta-analyses: The PRISMA statement. J Clin Epidemiol 2009; 62(10): 1006-12.

[http://dx.doi.org/10.1016/j.jclinepi.2009.06.005] [PMID: 19631508]

[12] Jena A, Shashirekha G. Effect of preoperative medications on the efficacy of inferior alveolar nerve block in patients with irreversible pulpitis: A placebo-controlled clinical study. J Conserv Dent 2013; 16(2): 171-4. [http://dx.doi.org/10.4103/0972-0707.108209] [PMID: 23716973]

[13] Saha SG, Jain S, Dubey S, Kala S, Misuriya A, Kataria D. Effect of oral premedication on the efficacy of inferior alveolar nerve block in patients with symptomatic irreversible pulpitis: A prospective, double-Blind, randomized controlled clinical trial. J Clin Diagn Res 2016; 10(2): ZC25-9. [JCDR].

[PMID: 27042580]

[14] Aggarwal V, Singla M, Kabi D. Comparative evaluation of effect of preoperative oral medication of ibuprofen and ketorolac on anesthetic efficacy of inferior alveolar nerve block with lidocaine in patients with irreversible pulpitis: A prospective, double-blind, randomized clinical trial. J Endod 2010; 36(3): 375-8.

[http://dx.doi.org/10.1016/j.joen.2009.11.010] [PMID: 20171350]

[15] Yadav M, Grewal MS, Grewal S, Deshwal P. Comparison of preoperative oral ketorolac on anesthetic efficacy of inferior alveolar nerve block and buccal and lingual infiltration with articaine and lidocaine in patients with irreversible pulpitis: A prospective, randomized, controlled, double-blind study. J Endod 2015; 41(11): 1773-7.

[http://dx.doi.org/10.1016/j.joen.2015.06.008] [PMID: 26410153]

[16] Kaufman E, Weinstein P, Milgrom P. Difficulties in achieving local anesthesia. J Am Dent Assoc 1984; $108(2): 205-8$. [http://dx.doi.org/10.14219/jada.archive.1984.0470] [PMID: 6584494]

[17] Dreven LJ, Reader A, Beck M, Meyers WJ, Weaver J. An evaluation of an electric pulp tester as a measure of analgesia in human vital teeth. J Endod 1987; 13(5): 233-8.

[http://dx.doi.org/10.1016/S0099-2399(87)80097-3] [PMID: 3473179]

[18] Potočnik I, Bajrović F. Failure of inferior alveolar nerve block in endodontics. Endod Dent Traumatol 1999; 15(6): $247-51$. [http://dx.doi.org/10.1111/j.1600-9657.1999.tb00782.x] [PMID: 10825834] 
[19] Lapidus D, Goldberg J, Hobbs EH, Ram S, Clark GT, Enciso R. Effect of premedication to provide analgesia as a supplement to inferior alveolar nerve block in patients with irreversible pulpitis. J Am Dent Assoc 2016; 147(6): 427-37. [http://dx.doi.org/10.1016/j.adaj.2016.01.006] [PMID: 26952243]

[20] Shankariah M, Mishra M, Kamath RA. Tramadol versus ketorolac in the treatment of postoperative pain following maxillofacial surgery. J Maxillofac Oral Surg 2012; 11(3): 264-70. [http://dx.doi.org/10.1007/s12663-011-0321-y] [PMID: 23997475]

[21] Shirvani A, Shamszadeh S, Eghbal MJ, Marvasti LA, Asgary S. Effect of preoperative oral analgesics on pulpal anesthesia in patients with irreversible pulpitis: A systematic review and meta-analysis. Clin Oral Investig 2017; 21(1): 43-52. [http://dx.doi.org/10.1007/s00784-016-1974-1] [PMID: 27837343]

[22] Praveen R, Thakur S, Kirthiga M. Comparative evaluation of premedication with ketorolac and prednisolone on postendodontic pain: A double-blind randomized controlled trial. J Endod 2017; 43(5): 667-73. [http://dx.doi.org/10.1016/j.joen.2016.12.012] [PMID: 28320541]

[23] Akhlaghi NM, Hormozi B, Abbott PV, Khalilak Z. Efficacy of ketorolac buccal infiltrations and inferior alveolar nerve blocks in patients with irreversible pulpitis: A prospective, double-blind, randomized clinical trial. J Endod 2016; 42(5): 691-5. [http://dx.doi.org/10.1016/j.joen.2016.02.003] [PMID: 26964901]

[24] Stentz D, Drum M, Reader A, Nusstein J, Fowler S, Beck M. Effect of a combination of intranasal ketorolac and nitrous oxide on the success of the inferior alveolar nerve block in patients with symptomatic irreversible pulpitis: A prospective, randomized, double-blind study. $\mathrm{J}$ Endod 2018; 44(1): 9-13.

[http://dx.doi.org/10.1016/j.joen.2017.09.011] [PMID: 29153730]

\section{(C) 2018 Sivaramakrishnan and Sridharan}

This is an open access article distributed under the terms of the Creative Commons Attribution 4.0 International Public License (CC-BY 4.0), a copy of which is available at: (https:/creativecommons.org/licenses/by/4.0/legalcode). This license permits unrestricted use, distribution, and reproduction in any medium, provided the original author and source are credited. 